Birungi, Huda, Motlaleng, Onjala and Sterner. 2002. Sri Lankan Journal of Agricultural Economics. Volume 4. Part 1. Pp. 73-93.

\title{
Ranking Environmental Services in Different Countries
}

\author{
B. Olsson, P. Birungi, S. Huda, G.R. Motlaleng, \\ J. Onjala and T. Sterner *
}

\begin{abstract}
Environmental policies to deal with global problems like climate change must be global and some form of environmental valuation at the international level would be a very useful input into decision making. However, such a valuation is likely to be so difficult that we need to consider whether it is possible at all. The purpose of this paper was to investigate how people in different socioeconomic settings and different countries view and value a number of environmental issues. We set out to see how people in widely different settings would rank different "environmental problems". The study was performed simultaneously in countries from four continents; Botswana, Brazil, Kenya, South Africa, Sri Lanka, Sweden and Uganda. The sample of countries varies by income, population growth, social indicators such as literacy and environmental resources. We found that most of the respondents were reasonably aware of environmental issues and there is a similar group of issues that dominates the environmental agenda in practically all the countries. There is for instance agreement on the fact that water and air pollution as well as waste management are important issues. Issues such as climate change, forest loss and the spread of toxic substances were also considered important in practically all countries. The results have proven to be reasonably in line with what might be expected.
\end{abstract}

The authors are, respectively, Ph.D Student in Environmental Economics, Gothenburg University, Sweden, Senior Lecturer in Economics, Makerere University, Uganda, Senior Lecturer in Economics, University of the Western Cape, South Africa, Senior Lecturer in Economics, University of Botswana, Senior Lecturer in Economics, Nairobi, Kenya, and Professor of Economics, Gothenburg University, Sweden. 


\section{Introduction}

Many important environmental problems are transboundary in nature and some are truly global, a typical case being global climate change. For such problems there may be considerable asymmetries in environmental consequences. Environmental policies to deal with this type of problem must be global and some form of environmental valuation at the international level would be a very useful input into decision making. However, such a valuation is likely to be so difficult that we need to consider whether it is possible at all. The area of nonmarket valuation has led to a prolific literature concerning the difficulties with methods that build on stated preferences, see for instance Freeman (1993), Diamond and Hausman (1994), Kahneman and Knetsch (1992) or finally Arrow et al., (1993) on the NOAA panel. Several of the problems are worse in situations where the environmental good is hard to conceptualise, the improvement abstract or hypothetical for the respondent and particularly when even the natural science mechanisms are hard to understand. Naturally, these problems tend to apply particularly to global environmental issues. One possible approach to valuation may be based on choice experiments through which different environmental attributes or services can be compared. For instance the respondent might face a choice between a project that benefits a local good like cleaner drinking water and one that deal with a global environmental problem. It is however far from clear how one might proceed with such work, particularly in a context where international comparisons are desired. The purpose of this paper was to see whether it was possible to come up with a single list of issues or concerns which people in widely different settings would identify as "environmental problems" and if so, to compare the rankings given to these issues.

For this purpose the same survey has been administered in a number of countries namely Botswana, Brazil, Kenya, South Africa, Sri Lanka, Sweden and Uganda. This article draws out the most important conclusions from the individual country reports (see further Birungi, 2001; Huda, 2001; Onjala, 2001; Olsson, 2001; Motlaleng and Makepe, 2001; Kotagama and Seneviratne, 2001; Lerda, 2001).

The countries included in this survey are very different from one another in several respects. To provide some background to the ranking of environmental problems in the different countries, Table 1 shows a summary of some 
environmental and economic indicators. Sweden represents the group of developed countries as the GDP/capita is very high. (Note however that there are many other relevant differences than those highlighted here).

As we can see, the sample of countries varies by both income, population growth, social indicators such as literacy and environmental resources. Starting with the latter, the sample splits broadly into two categories. Kenya, South Africa, Sri Lanka and Uganda have much less water, forest and land resources per capita than Botswana, Sweden and Brazil. Sri Lanka has particularly visible scarcity when it comes to physical availability of land, Kenya is most lacking in forest and South Africa has its most dramatic shortage when it comes to water rather than the other natural resources.

Table 1:

Environmental and economic indicators

\begin{tabular}{|c|c|c|c|c|c|c|c|}
\hline & Kenya & $\begin{array}{l}\text { South } \\
\text { Africa }\end{array}$ & $\begin{array}{l}\text { Sri } \\
\text { Lanka }\end{array}$ & Uganda & Botswana & Sweden & Brazil \\
\hline $\begin{array}{l}\text { Freshwater } \\
\text { Resources } \\
\mathrm{m}^{3} / \text { capita }\end{array}$ & 1 & 1 & 2 & 3 & 9 & 20 & 42 \\
\hline $\begin{array}{l}\text { Forest resources } \\
\left(\mathrm{km}^{2} / 1000\right. \\
\text { capita })\end{array}$ & 0.5 & 2 & 1 & 2.9 & 87 & 27 & 33 \\
\hline $\begin{array}{l}\text { Land area } \\
\left(\mathrm{km}^{2} / 1000 \text { capita }\right)\end{array}$ & 20 & 30 & 3 & 10 & 354 & 46 & 51 \\
\hline $\begin{array}{l}\text { Urban } \\
\text { population } \\
\% \text { of total pop }\end{array}$ & 31 & 53 & 23 & 14 & 49 & 83 & 80 \\
\hline $\begin{array}{l}\text { Tons of } \mathrm{CO}_{2} \\
\text { emis sions / } \\
\text { capita }\end{array}$ & 0.2 & 7.3 & 0.4 & 0.1 & 1.4 & 6.1 & 1.7 \\
\hline $\begin{array}{l}\text { Literacy rate }(\%) \\
\text { male age }>15 y r s\end{array}$ & 12 & 15 & 6 & 24 & 27 & 100 & 16 \\
\hline $\begin{array}{l}\text { Pop.growth (\%) } \\
1980-98\end{array}$ & 3.1 & 2.3 & 1.3 & 2.7 & 3.0 & 0.4 & 1.7 \\
\hline GDP / capita & 0.4 & 3 & 0.8 & 0.3 & 3 & 25 & 5 \\
\hline
\end{tabular}

Source: World Bank (2000) 
It is natural to believe that these shortages might be reflected in the priorities people have in the respective countries. There are also strong relationships between environmental and economic indicators even if they do not necessarily correlate. When it comes to urbanisation and carbon emissions, South Africa is more like Sweden while Botswana is more like the first group of countries. When it comes to income there are clearly three groups, Sweden being in a category of its own while Brazil, South Africa and Botswana are somewhat intermediate. For population growth and literacy Sweden is again somewhat of an outlier.

People within each country have different values and preferences depending on what they experience in their work as well as in their homes and neighbourhoods. The experience and information people have is inevitably formed partly by their everyday life and partly by the knowledge and values they have formed through life. This study is especially interested in people's environmental preferences and tries to find out whether people in different socio-economic contexts and different countries have sufficiently similar preferences that it is at all meaningful to compare and maybe aggregate rankings. We also wonder how the rankings of global versus local environmental problems depend on socio-economic conditions. This question applies both to income and other variables. We are interested in variation between as well as within countries (for example comparing urban and rural areas).

\section{Methodological Issues}

The ranking serves several purposes. One is to remind the respondent of the high number of environmental issues surrounding us today. This is very important to bear in mind when stated preference studies are undertaken since there is a risk that people will put all their "environmental budget" into one symbolic item if they are only asked about one such item. Putting any one environmental issue in a larger environmental context is very important for the validity of the answers. The main purpose here is to explore how the environmental preferences of the respondents vary depending on country and socioeconomic variables such as residential area (urban or rural).

\section{Data Collection}

Before the survey was administered it was subjected to a couple of pilot tests. This was performed in the participating 
countries; in Sweden for example, this was done among students at the Department of Economics at Gothenburg University. They were asked to comment on the questions and they were also invited to discuss the difficulties of responding. There have also been discussions between the responsible researchers from the other participating countries. This lead to some minor variations between the surveys but care was taken to minimise the changes so that the studies were still comparable. All surveys were conducted the same way with reservation for locally decided sampling procedures.

In Sweden a simple random sample was undertaken and the survey instrument was a questionnaire mailed in March and April 1998 to 800 people between 18 and 75 years old. A random survey is in principle desirable but many countries do not have the kind of population census files that make randomised selection possible in this sense and thus other mechanisms were used.

In Botswana, the selected areas were Tlokweng, Mogoditshane, Kgale View, Broadhurst and Extension 9 in Gaborone, to obtain representative demographic, socio- economic and other human attributes. A total of 494 face-to-face interviews were obtained.

In Brazil, a random sample of 750 households was selected among 75 geographic areas of the Federal District (where the capital is located), stratified by income level. ${ }^{1}$

In Kenya, a total of 473 respondents from Nairobi, Kisumu and Webuye were interviewed. In each region two equal sub-samples were selected on the basis of stratification such as income, sex, and location for each sub-sample group.

In South Africa a simple random sample concentrated in the Western Cape and Eastern Cape regions was conducted. About 150 individuals were selected for face-to-face interviews and about 100 were telephoned to respond to the questionnaire.

In Sri Lanka the total sample was 500 respondents, stratified as rural (200) and urban (300). The sample units were selected randomly, as random clusters of villages in rural areas and streets in urban areas. The selected urban area was Negambo, located 20 miles away from the answered. 
capital city Colombo. The rural areas were Danture (100), Mahalllupallama (100), and Knuckles (100).

In Uganda, data were obtained by stratified random sampling according to income. In the urban areas Kololo, Ntinda and Makerere University staff quarters were used as the high and middle income class while the sub-urban areas of Katang and Bwise represented the low income class. Three rural areas were also covered in the districts of Kabarole in the west, Rukungiri in the south west and Mbale in the east. These were simple random samples. Altogether 527 respondents were directly interviewed.

The survey questionnaire consisted of two sections. Section A, asked participants to give priority to four out of fifteen environmental issues. Included were such issues as should be relevant across a wide range of persons. Section $B$ was to provide data about the respondent. It focuses on gender, age, where the respondent grew up, occupation and whether the respondent was living in a rural or urban residential area. It also included marital status, monthly gross income, spouse's monthly gross income and number of children. Furthermore the respondent is asked for educational length and subject and also for level of "environmental awareness".

Ranking might depend on how familiar or unfamiliar events are if people's value constructs are substantially more developed for the former of these. This will be related to whether they are able to make more rational and consistent decisions (rankings) for more familiar events. The notion familiar is defined according to how personally relevant or local the issue in question is. (These concepts sometimes coincide. Although unfamiliar issues might also be personally relevant, at least they are considered in a more global perspective and therefore implicitly more abstract and intangible.)

Environmental issues may vary along several dimensions, two of which are familiarity and tangibility (how local the issues are). These dimensions do not necessarily coincide, but the categorisation may nevertheless be more or less arbitrary. Local air pollution for example may be much more familiar and relevant to people living in urban areas than to people in rural parts of the country. One categorisation is illustrated in Table 2. 
Table 2: $\quad$ Familiarity and tangibility among environmental problems

\begin{tabular}{llll}
\hline & Familiar & Less familiar & Unfamiliar \\
\hline Local & Waste management, & Air pollution, & Spread of poisonous \\
& Drinking water & Soil erosion & metals and chemicals \\
Global & Biodiversity loss & Climate change & Ozone layer \\
& & & deterioration \\
\hline
\end{tabular}

We should also distinguish 800 respondents were sampled. between potential and actual Fifteen questionnaires were returned environmental problems. What is an to sender because of unknown actual problem in one country may residence. Through telephone, two only be a potential problem in have been reported deceased and another. A good example is clean drinking water. In some of the countries within the survey, there are problems with the supply of drinking water to the population. In Sweden, however, there are practically no problems supplying drinking water. Hence people may take this supply more or less for granted, depending on knowledge and experience. However if they know that water is a problem in other places the respondents might still see it as a potential problem, even in Sweden, or they may be referring specifically to water shortage as a global problem.

\section{Data Analysis / Ranking of Environmental Issues}

In this section we start by analysing the Swedish data since it was a little more detailed. In Sweden some have explained why they did not participate. Nine people have sent back the questionnaire without filling it in, sometimes with a note stuck on it explaining their reasons (included in Non-responses). Sixty questionnaires were discarded due to misunderstandings and incomplete responses. The total effective sample remained at 247 respondents (Table $3)$.

In order to obtain a better validation of the results it is important to be aware of the degree to which the sample represents the population. Here it is important to compare with detailed demographics and therefore the Swedish sample will be compared with population data from the Swedish Bureau of Statistics. Tables 4 to 6 below show these together with the sample characteristics. Where available we 
have also included data from the other countries.

The mean age of the respondents in Sweden was 43.1 years. In Kenya, the mean age of the respondents was 33.6 years. As seen in Table 4, the sample is not quite representative. Respondents between 25-64 years old are over-represented compared to those between 65-75 years old.

In Sweden, women were somewhat over-represented in the sample (58 per cent), while their population share is 51 per cent. This discrepancy may come from a larger extent of either tolerance or time among the female part of the population. Work-time outside the home is in general longer for men. This means that women are in their homes a larger part of the day than men and therefore would have more time and tolerance to respond to a mail survey like this one. In South Africa 48 per cent and in Kenya 30 per cent of the respondents were female.

Income generally follows education and both income and educational level are somewhat higher in the Swedish sample than in the population. Higher education usually implies a higher propensity to respond to surveys of this kind, but the difference between sample and population mean was small (12 years versus 11 years of education and US\$ 1,300 versus US\$ 1,100 of income respectively). In Kenya, mean income in the survey was US\$ 209 which is also above mean income. While the respondents in Sweden were not asked for wealth or capital belongings, among the most common assets owned by respondents in Kenya were agricultural land $(30 \%)$ and other small business (26\%) which provided additional sources of income. It has to be remembered that household capital belongings can differ greatly between countries and can thus influence the results.

Level of education is complicated to compare between countries. In Kenya nearly 50\% had some secondary education while only $1 \%$ had no formal education. The mean level of education in years for the Swedish sample and population is given in Table 6. (Secondary education is equivalent to about twelve years of education in Sweden). The mean size of households in the Swedish sample was slightly higher than population average. The discrepancy comes mainly from an under-representation of single person households.

People stating that they are living in urban areas are underrepresented in the Swedish sample. These are however subjective statements and 
have not been objectively verified. The official determinants of a What should be characterised as rural/urban area are not known, urban in relation to rural can be instead the respondents were asked difficult. Closeness to nature, level of to state what their opinion of the noise, transportation facilities, matter was.

distance from central business areas

etc need not be good determinants.

Table 3: $\quad$ Response rate of Swedish survey

\begin{tabular}{lc}
\hline & Number \\
\hline Original Sample Size & 800 \\
Unknown residence & 15 \\
Deceased & 2 \\
Non-responses & 476 \\
Incomplete questionnaires & 60 \\
Total effective sample & 247 \\
\hline
\end{tabular}

Table 4:

Age distribution of respondents in Sweden and Kenya

\begin{tabular}{llll}
\hline Age & $\begin{array}{l}\text { Swedish } \\
\text { sample } \\
\text { share }(\%)\end{array}$ & $\begin{array}{l}\text { Swedish } \\
\text { population* } \\
\text { share }(\%)\end{array}$ & $\begin{array}{l}\text { Kenyan } \\
\text { sample } \\
\text { share }(\%)\end{array}$ \\
\hline $18-24$ & 12.0 & 11.1 & 17 \\
$25-44$ & 40.9 & 35.3 & 73 \\
$45-64$ & 38.0 & 31.1 & 10 \\
$65-75$ & 9.0 & 22.4 & \\
Mean & 43.1 years & 40.0 years** & 33.6 years \\
\hline
\end{tabular}

*Source: SCB 1998

**pers. com. Christer Funck, SCB (m=38,7 yrs; f=41,3yrs) 
Table 5: $\quad$ Gender distribution

\begin{tabular}{lllll}
\hline Gender & $\begin{array}{l}\text { Swedish } \\
\text { sample }\end{array}$ & $\begin{array}{l}\text { Swedish } \\
\text { population* }\end{array}$ & $\begin{array}{l}\text { Kenyan } \\
\text { sample }\end{array}$ & $\begin{array}{l}\text { South African } \\
\text { sample }\end{array}$ \\
\hline Female & $58 \%$ & $51 \%$ & $30 \%$ & $48 \%$ \\
\hline
\end{tabular}

*Source: SCB 1998

Table 6: $\quad$ Some sample and average characteristics for Sweden

\begin{tabular}{lll}
\hline & Swedish sample (\%) & Swedish pop* (\%) \\
\hline Education mean & 12.2 years & 11.5 years \\
Income in US\$ & 1,355 & 1,128 \\
Household mean size & 2.5 persons & 2.1 persons \\
Urban residence & $62 \%$ & $84 \%$ \\
\hline
\end{tabular}

*Source: SCB 1998. Exchange rate used: 1 US\$ = 7.8 SEK.

\section{Empirical Results}

In this section we will present the findings of the investigation. Table 7 below shows that most of the respondents were (or consider themselves) very or reasonably aware of environmental issues. We see that Uganda and Sweden have similar distribution of awareness. Kenya has also a similar share of respondents stating they were little aware, but a much larger share of 'very aware' respondents. In Botswana, 70 per cent of the respondents said they were aware of environmental problems. We also asked how difficult the respondent found the ranking. This is an indication of the extent to which the results were true reflections of the respondents' preferences and also of how elaborate the answers were. In Uganda, 52 per cent thought it was rather easy to make a ranking decision and $30 \%$ found it rather difficult. In Botswana, 55 per cent confirmed that the ranking was difficult.

The ranking list is intended to provide information about the environmental preferences; what constitutes an environmental problem and which is given the highest priority. It was identical to all respondents in all countries to facilitate comparison although this 
Table 7: $\quad$ Stated degree of environmental awareness

\begin{tabular}{lllll}
\hline Awareness (\%) & Sweden & Kenya & Botswana & Uganda \\
\hline Very & 14.5 & 27 & 70 & 13.9 \\
Reasonably & 72.6 & 59 & & 70.4 \\
Little & 12.9 & 13 & 30 & 11.6 \\
\hline
\end{tabular}

could on the other hand cause some sequence bias. The respondents were free to add items of their own to the list but few additions were made, perhaps indicating that the list was fairly complete.

The ranking concerned what the respondent thought to be the biggest problem. Apart from those who could not give priority to any of the problems "because they were equally important", the respondents may have interpreted the question differently on this point, i.e. as a question of issues rather than problems. An environmental issue may be seen as a potential problem and therefore raise concern among people.

Looking first at the developed country, Sweden, the environmental issue which was given the highest priority was 'contaminated water'. Several of the respondents have commented on the questionnaire saying that water is essential to life. There are in general no serious health problems with Swedish water supply and water is abundant in Sweden (see
Table 1). It is thus possible that some respondents were thinking of problems on a global rather than local scale. However, just prior to the survey there had been a large media attention on an incident in the southwest of Sweden a short time prior to the investigation. In a tunnel project the poisonous chemical acrylamide leaked out into the groundwater. Cattle died and people had to rely on water from tanks for some time. This was an important news issue at the time and people in Sweden were reminded of how essential clean drin king water is. It is reasonable to believe that this incident caused Swedish survey respondents to rank 'drinking water' and perhaps also 'poisonous chemicals' higher than they otherwise would.

The other main explanation to the high rank of 'contaminated water' is that it is an effect of people's concern for other countries. It is widely known that water is a very scarce resource in many countries, especially in Africa and Asia. This explanation is however 
contradicted by the fact that other non-Swedish problems are not as highly ranked. For instance, countries with water problems often have other environmental problems as well, like deforestation and soil erosion. Soil erosion was ranked far from contaminated water.

Table 8 shows the outcome of the ranking in Sweden. The respondent was supposed to rank the four most important problems and the second column -"Priority" shows the number of first-hand, second-hand, third-hand and fourthhand votes each issue received, respectively.

There are different ways of weighting these votes. First we can take into account all four votes giving them equal weights. This is done in the third column. Second, we can weigh the votes as in the fourth column; first-hand vote is weighed four times the fourth-hand vote. The votes can also be given exponential weights (see last column). Another way is to take into account only the first-hand vote and thus give it an infinite weight. To do this is to look only at the first-hand votes (Priority 1 in Table 8). There is no single "correct" method. However, putting equal weights on the votes is not reasonable; it is more realistic to differentiate the weights, giving more weight to the highest ranked issue or vote. In Table 8, different weights are given in different columns for comparison.

Independently of weights, the two most highly rated issues are found to be contaminated water and local air pollution. For the first three weighting methods, at least the order of the first five issues are the same. Looking more closely at the table, it can be noted that some issues have fewer first-hand votes than second, third or fourth-hand ones. 'Waste' for example has 11 third-hand but not a single first-hand vote.

Table 8: $\quad$ Environmental ranking results in Sweden

\begin{tabular}{|c|c|c|c|c|c|c|c|c|c|c|c|}
\hline & \multicolumn{4}{|c|}{ Priority } & \multicolumn{2}{|c|}{$\begin{array}{l}\text { Equal } \\
\text { weights }\end{array}$} & \multicolumn{2}{|c|}{$\begin{array}{l}\text { Weights: } \\
1=4 w, 2=3 w, \\
3=2 w, 4=1 w\end{array}$} & \multicolumn{2}{|c|}{$\begin{array}{l}\text { Weights: } \\
1=8 w, 2=4 w, \\
3=2 w, 4=1 w\end{array}$} & \multirow{2}{*}{ 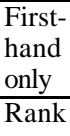 } \\
\hline & 1 & 2 & 3 & 4 & Sum & Rank & Sum & Rank & Sum & Rank & \\
\hline Drinking Water & 70 & 33 & 31 & 17 & 151 & 1 & 458 & 1 & 771 & 1 & 1 \\
\hline Air pollution & 48 & 43 & 28 & 28 & 147 & 2 & 405 & 2 & 640 & 2 & 2 \\
\hline $\begin{array}{l}\text { Poisonous } \\
\text { chemicals }\end{array}$ & 25 & 46 & 30 & 33 & 134 & 3 & 331 & 3 & 477 & 3 & 4 \\
\hline
\end{tabular}


'Seas and lakes' have more than twice as many second-hands as firsthands and the opposite is true for 'radioactivity' -24 first-hands versus only 12 second-hands. This phenomena could be called polar or polarised rankings and may be interpreted as situations where 'radioactivity', for example, means a great deal to some people and very little to other people ${ }^{2}$.

When only first-hand votes are taken account of, 'radioactivity is ranked number five instead of number seven. And 'Others' places itself at number eight. 'Others' include: the overpopulation, genetic engineering and food quality, teach our children to respect nature, people careless of nature, human stress. Note that 'others' is not a homogeneous category.

In Table 2, we classified the problems climate change and the ozone layer as global or general problems while air pollution and spread of toxic metals and chemicals (poison) as local. This should then be reflected in the ranking as a more even distribution of the votes over countries for the global problems. At the same time problems with water and waste were expected to be smaller in industrialised or developed countries than in developing.

Taking a look at Table 9 we can compare the Swedish results with results from some of the other studies in this project. South Africa and Kenya had similar results for air pollution and contaminated water. In Sri Lanka, the deforestation was ranked as the most important problem. The related issue of soil erosion was close in rank as number three. Kenya and Sri Lanka are the countries with the least forest area per capita (see Table 1 above), but Kenya does not rank deforestation as highly as Sri Lanka, in spite of having relatively little forest.

A reason why air pollution was so highly ranked in Kenya was that $80 \%$ ranked it as number one in the Webuye region which is known for its severe air pollution problems from mainly the pulp and paper industries in the region. Without this "Webuye effect" 2 contaminated water would have been ranked first

The exact interpretation of 'radioactivity' is another question. Some people may think of the issues related to nuclear power-plant incidents or nuclear armaments. Natural radioactivity from the ground such as Radon in houses is another possibility. See Onjala (2001). 
Waste was also ranked highly in the African countries where it is often a very visible problem. Although in Botswana it was ranked number one, 53 per cent of the respondents were satisfied with their waste management collection services. It is possible that respondents have perceived it as a societal or national problem as opposed to perceiving it as a problem in their own areas. As in Uganda, with the growth in population more hazardous waste have penetrated the rural areas and the compost pits come even closer to one another. When it rains these are the main sources of water contamination. Looking at Table 1 we see that in the African countries Botswana, Kenya and Uganda, the rural population density is very high compared to other countries, which help explain the problem of rural waste management. In the cities, the garbage is dumped on the road side or in dust bins and the responsible municipal authorities collect less than 50 percent of the generated waste and dump it in wetlands surrounding the towns. In Kenya, poisonous metals and chemicals were ranked high but not so in Uganda.

In Uganda, respondents considered climatic changes as the worst problem. This might be explained by the fact that the country is agricultural with more than 80 per cent employed by that sector ${ }^{5}$. Climatic changes would have significant effects on agricultural output and people might be worried by increased heat and reduced rains. The high rate could also be explained by the presence of the El-Nino weather phenomenon which hit the East African region for the period of six months or more. Another possible explanation could be the rise in malaria disease in Rukungiri and Mbale where malaria has not been a big problem before. People seem to associate this with changes in weather patterns as these used to be cold, hilly areas with minimal incidence of malaria. With the reclaiming of wetlands as a result of population pressure and search for arable land along with other factors, the weather patterns have changed signif icantly.

However, this was not reflected so clearly in Uganda's neighbouring country Kenya, where climatic changes were ranked number five. In fact, in both the Nairobi and Kisumu regions only about $2 \%$ of the respondents ranked climate change as number one.

\begin{tabular}{ll}
\hline 4 & See Motlaleng and Makepe (2001). \\
5 & See Birungi (2001).
\end{tabular} 
The rankings in Table 9 have equal weights. Giving more weight to higher rankings, a somewhat

different pattern appears. Table 10 shows the rankings with "exponential weights", as in Table 8 for Sweden.

Table 9:

Ranking in different countries (equal weights)

\begin{tabular}{lllllllll}
\hline & Sweden & $\begin{array}{l}\text { Sri } \\
\text { Lanka }\end{array}$ & Uganda & Kenya & Botswana & Brazil & $\begin{array}{l}\text { South } \\
\text { Africa }\end{array}$ & $\begin{array}{l}\text { Total } \\
\text { rank }\end{array}$ \\
\hline Air poll. & 2 & 5 & 6 & 1 & 2 & 1 & 1 & 1 \\
Water & 1 & 2 & 3 & 3 & 6 & 4 & 2 & 2 \\
Waste & 9 & 6 & 2 & 4 & 1 & 2 & 3 & 3 \\
Climate change & 8 & 9 & 1 & 5 & 4 & 9 & 7 & 4 \\
Soil erosion & 12 & 3 & 4 & 8 & 3 & 10 & 6 & 5 \\
Ozone & 4 & 12 & 9 & 6 & 7 & 5 & 4 & 6 \\
Noise & 16 & 13 & 7 & 11 & 5 & 14 & 5 & 7 \\
Acid Rain & 11 & & & 15 & & 3 & 8 & \\
Poison. met & 3 & 4 & 8 & 2 & & 6 & & \\
Biodiversity & 10 & 11 & 10 & 7 & & 7 & & \\
Forest loss & 5 & 1 & 5 & 9 & & 15 & & \\
Seas\& lakes & 6 & 10 & 11 & 10 & & 12 & & \\
Radioactiv & 7 & 14 & 12 & 12 & & 8 & & \\
Wildlife & 13 & 7 & 13 & 13 & & 13 & & \\
Fish\& Game & 14 & 8 & 15 & 14 & 8 & 11 & & \\
Other & 15 & 15 & 14 & & & 16 & & \\
\hline
\end{tabular}

Table 10: $\quad$ Ranking in different countries (exponential weights: $w 1=8$, $\mathrm{w} 2=4, \mathrm{w} 3=2, \mathrm{w} 4=1$ )

\begin{tabular}{lllllllll}
\hline & Sweden & $\begin{array}{l}\text { Sri } \\
\text { Lanka }\end{array}$ & Uganda & Kenya & Botswana & Brazil & $\begin{array}{l}\text { South } \\
\text { Africa }\end{array}$ & $\begin{array}{l}\text { Total } \\
\text { weights }\end{array}$ \\
\hline Water & 1 & 2 & 3 & 1 & 6 & 3 & 2 & 18 \\
Air pollution & 2 & 5 & 6 & 2 & 2 & 1 & 1 & 19 \\
Waste & 11 & 6 & 1 & 3 & 1 & 4 & 3 & 29 \\
Climate ch. & 8 & 8 & 2 & 6 & 4 & 9 & 7 & 38 \\
Soil erosion & 14 & 3 & 4 & 5 & 3 & 12 & 6 & 47 \\
Ozone & 4 & 11 & 9 & 7 & 7 & 6 & 4 & 48 \\
Noise & 16 & 13 & 8 & 8 & 5 & 14 & 5 & 69 \\
Poison.met & 3 & 4 & 7 & 4 & & 2 & & 20 \\
Forest loss & 5 & 1 & 5 & 8 & & 5 & & 24 \\
Acid Rain & 10 & & & 13 & & 15 & 8 & 46 \\
Seas/lakes & 7 & 9 & 12 & 10 & & 7 & & 45 \\
Biodiv. & 9 & 12 & 10 & 11 & & 11 & & 53 \\
Radioactiv & 6 & 14 & 13 & 12 & & 10 & & 55 \\
Wildlife & 12 & 7 & 14 & 15 & & 8 & & 56 \\
Fish\& Game & 15 & 10 & 15 & 14 & 8 & 13 & & 75 \\
Other & 13 & 15 & 11 & 16 & & 16 & & 71 \\
\hline
\end{tabular}


There are small differences, especially for the most highly ranked issues. If we add the ranks for each issue, we get the same sum for the top two (13), but if we compare how many 1's each issue get, we see that in Table 8, air pollution had two and was ranked number one. Here we rank water as number one since it received two 1's.

\section{Urban and Rural (Regional) Ranking}

Table 11 shows the differences in ranking of the environmental issues in Sweden between people living in rural and urban areas respectively. When the four votes were equally weighed, we can spot a difference in ranking the issues.

The issues where urban and rural preferences differ the most were 'contaminated water' $\left(3^{\text {rd }}\right.$ and $1^{\text {st }}$ respectively), 'poisonous metals and chemicals' ( $2^{\text {nd }}$ and $4^{\text {th }}$ respectively), 'biodiversity' $\left(11^{\text {th }}\right.$ and $9^{\text {th }}$ respectively) and 'noise' $\left(13^{\text {th }}\right.$ and $15^{\text {th }}$ respectively). The differences in rural and urban ranking show some surprising results. Rural people rank 'local air pollution' as the most important environmental issue, while urban people rank 'contaminated water' as number one. Urban areas are usually more polluted than rural areas, which would give reason to believe that air pollution is a larger problem in such areas. However, this is not reflected in the ranking.

It is in principle possible that we are looking at issues related to the selection of dwelling location. Hence people who are worried about air pollution might be the ones who chose to live in the countryside. The explanation would be that people sensitive to air pollution live in less polluted areas. Hence, rural people are more sensitive to air pollution than urban people, although rural areas are less polluted. Another explanation is that people do not migrate, instead they adapt by and by to prevailing circumstances. This explains the lower ranking of noise amongst urban people; they are more or less unconscious of the perpetual noise. Noise can be far more vexing in the countryside. A further explanation could be rationalisation. People living in urban areas rationalise that by "playing down" the dangers and problems of air pollution.

The fact that biodiversity is higher ranked amongst urban people is another "anomaly". Perhaps people living in rural areas have better knowledge of the great diversity of plants and animals. Therefore a single species would have a relatively lower value and 
hence extinction of that species be a relatively lesser problem. Urban people would thus place a higher value to a single species because they believed the diversity of nature to be smaller (this is however a somewhat far-fetched hypothesis).

In Kenya the difference was largely between Webuye on the one hand and Nairobi and Kisumu on the other (Table 13). As commented on above, in the small urban centre Webuye more than $80 \%$ of the respondents ranked air pollution as number 1. In both Nairobi and Kisumu, approximately $45 \%$ of the respondents ranked quality and reliability of drinking water as their first priority, while $23.5 \%$ in Nairobi and $18 \%$ in Kisumu ranked air pollution as number 1 . In Kisumu, standing at the shores of Lake
Victoria, 4\% ranked threats to seas and lakes as number 1 , compared to zero in Nairobi and Webuye.

The higher rank of poisonous chemicals among people in rural areas could probably be explained as an effect of the problems in the south of Sweden outlined above. Those problems affected mainly people with their own water wells. The municipal water systems were not affected and thus neither were people in urban areas. In Botswana the differences in ranking between the regions Tlokweng, Mogaditshane, Broadhurst and Kgale View were very small. In Kgale View, people ranked noise higher than in any of the other regions. Instead, climate change was ranked lower (see Table 12).

Table 11: $\quad$ Ranking in Sweden (equal weights)

\begin{tabular}{lll}
\hline Rank & Rural ranking & Urban ranking \\
\hline 1 & Air pollution & Drinking water \\
2 & Poison & Air pollution \\
3 & Drinking water & Ozone \\
4 & Ozone & Poison \\
5 & Forests & Forests \\
6 & Seas \& lakes & Seas \& lakes \\
7 & Radioactivity & Radioactivity \\
8 & Climate change & Climate change \\
9 & Waste & Biodiversity loss \\
10 & Acidification & Waste \\
11 & Biodiversity & Acidification \\
12 & Soil erosion & Soil erosion \\
13 & Noise & Wildlife \\
14 & Wildlife & Fish\&game \\
15 & Fish\&game & Noise \\
16 & Others & Others \\
\hline
\end{tabular}


Table 12: $\quad$ Ranking in Botswana by region

\begin{tabular}{lcccc}
\hline & \multicolumn{2}{c}{$(\mathrm{R}$ U R A L ) } & \multicolumn{2}{c}{ ( U R B A N ) } \\
\cline { 2 - 5 } & Tlokweng & Mogaditshane & Broadhurst & Kgale View \\
\hline Waste & 1 & 1 & 1 & 1 \\
Air Pollution & 2 & 2 & 1 & 2 \\
Soil Erosion & 3 & 3 & 3 & 3 \\
Climate change & 4 & 4 & 4 & 5 \\
Noise & 5 & 5 & 5 & 4 \\
Water & 6 & 6 & 6 & 6 \\
Ozone & 7 & 7 & 7 & 7 \\
Fish \& Game & 8 & 8 & 8 & 8 \\
\hline
\end{tabular}

Table 13: $\quad$ Ranking in Kenya by region

\begin{tabular}{lccc}
\hline & Nairobi & Kisumu $\left(3^{\text {rd }}\right.$ city) & Webuye (small) \\
\hline Air Pollution & 2 & 2 & 1 \\
Poison & 6 & 5 & 4 \\
Water & 1 & 1 & 2 \\
Waste & 3 & 3 & 4 \\
Climate change & 7 & 7 & 7 \\
Ozone & 4 & 8 & 7 \\
Biodiversity & 10 & 9 & 7 \\
Soil erosion & 5 & 4 & 3 \\
Deforestation & 8 & 9 & 7 \\
Seas \& Lakes & 13 & 6 & 7 \\
Radioactivity & 9 & 8 & 7 \\
Noise & 11 & 8 & 6 \\
Wildlife & 13 & 9 & 7 \\
Fish \& Game & 13 & 9 & 7 \\
Acid Rain & 13 & 9 & 5 \\
Others & 12 & 8 & 7 \\
\hline
\end{tabular}




\section{Concluding Discussion}

The purpose of this paper was to investigate how people in different socio-economic settings and different countries view and value a number of environmental issues. The study was performed simultaneously in several different countries; Botswana, Brazil, Kenya, South Africa, Sri Lanka, Sweden and Uganda.

The results have proven to be reasonably in line with what might be expected. There is a group of issues that dominates the environmental agenda in practically all the countries. There is for instance agreement on the fact that water and air pollution as well as waste management are important issues. Issues such as climate change, forest loss and the spread of toxic substances were also considered important in practically all countries.

Overall, contaminated water and local air pollution were found to be the two problems given the highest priority. In Sweden contaminated water was the number one priority although there are no real environmental problems with the Swedish water supply. However, it may be thought of as a potential or an international problem. (There was also the incident of poisonous leakage in the south of Sweden, which may have affected the Swedish respondents).

There were some cases where the ranking could clearly be related to local events. Forest loss was very important in one country (Sri Lanka) where this has in fact been an important issue. Likewise the issue of soil loss is more important in Botswana and Sri Lanka than in countries like Sweden. Similarly we see some local issues that are not considered important like waste management in Sweden which is basically an issue that is already well taken care of there.

To further cast light on the difference between local and global issues, we studied the difference in ranking between people in rural and urban areas. In the Swedish case, people in rural areas rank local air pollution and noise more highly than urban people do. One explanation for these 'anomalies' could be decreasing marginal damages. In rural areas without air pollution and noise, the marginal damage of a jetplane passing by for example, is higher than in urban areas, where noise and pollution are more common to people. It could also be the way people choose to live and the way they interpret questionnaires. 
In Botswana the differences in ranking between the regions were very small but in Kenya, they were more significant. Contaminated water was seen more important in Nairobi and Kisumu than in Webuye. In Webuye, the most important problem is heavy local air pollution which was clearly reflected in the survey answers and even affected the mean values for Kenya as a whole. This serves to remind us of the importance of controlled and representative samples.

\section{Acknowledgements}

This paper builds on a series of working papers by the same group of authors plus H.B. Kotagama, Department of Agricultural Economics, University of Peradeniya, Sri Lanka, and A. Seneviratne Department of Agricultural Economics, University of Peradeniya, Sri Lanka.

\section{References}

Arrow, K, Solow, R, et al. (1993). Report of the NOAA Panel on Contingent Valuation. Federal Register, 58:46024614.

Birungi, P. (2001). Multi-Nation Contingent Valuation: The Case of Uganda, Working Paper, 16, Environmental
Economics Unit, Gothenburg University.

Diamond, P.A. and J.A. Hausman (1994). Contingent Valuation: Is Some Number Better than No Number? Journal of Economic Perspectives, 8(4): 45-64.

Freeman, M. (1993). The Measurement of Environmental and Resource Values, Resources for the Future, Washington DC.

Huda, S. (2001). Multi-Nation Contingent Valuation: The Case of South Africa. Working Paper, 14, Environmental Economics Unit, Gothenburg University.

Kahneman, D. and J.L. Knetsch (1992). Valuing Public Goods: The Purchase of Moral Satisfaction. Journal of Environmental Economics and Management, 22:57-70.

Kotagama, H.B. and A. Seneviratne (2001). Multi-Nation Contingent Valuation: The Case of Sri Lanka. Working Paper, 18, Environmental Economics Unit, Gothenburg University. 
Lerda, S. (2001). Multi-Nation Contingent Valuation: The Case of Brazil. Working Paper, 19, Environmental Economics Unit, Gothenburg University.

Motlaleng, G.R. and P.M. Makepe (2001). Multi-Nation Contingent Valuation: The Case of Botswana. Working Paper, 17, Environmental Economics Unit, Gothenburg University.

Onjala, J.O. (2001). Multi-Nation Contingent Valuation: The Case of Kenya. Working Paper, 15, Environmental Economics Unit, Gothenburg University.
Olsson, B.T. (2001). Multi-Nation Contingent Valuation: A comparative study of ranking and values of environmental problems. Working Paper, 13, Environmental Economics Unit, Gothenburg University.

SCB, Statistiska meddelanden Tabell (1998). Familjer fördelade på disponibel inkomst (Swedish).

SCB (1998). Statistisk Årsbok Statistical Yearbook.

SCB (1998). Christer Funck, personal communication.

World Bank (2000). World Development Indicators, World Bank. 